\title{
Development of Parasomnias From Childhood to Early Adolescence
}

\author{
Luc Laberge, MSc* $\ddagger$; Richard E. Tremblay, PhD $\ddagger$; Frank Vitaro, PhD $\ddagger$; and \\ Jacques Montplaisir, MD, $\mathrm{CRCP}(\mathrm{c}), \mathrm{PhD}^{*} \S$
}

\begin{abstract}
Objectives. This study examines the prevalence and developmental changes of parasomnias and assesses gender differences, relationships between parasomnias, and associations with anxiety and family adversity using data collected during the course of a longitudinal study of a representative sample of children from Québec.

Method. The present analyses are based on results available for 664 boys and 689 girls for whom mothers have completed questions concerning demographics, parasomnias, and anxiety level. For the prevalence and developmental aspects of parasomnias, prospective data were collected at annual intervals from 11 to 13 years old and retrospective data for the period between ages 3 and $\mathbf{1 0}$ years were collected when the children were $\mathbf{1 0}$ years old.
\end{abstract}

Results. Somniloquy, leg restlessness, and sleep bruxism are the most frequent parasomnias. More girls were afflicted with leg restlessness, while enuresis and somniloquy were more common in boys. High anxiety scores were found in children suffering from night terrors, somniloquy, leg restlessness, sleep bruxism, and body rocking. Parasomnias were unrelated to the index of family adversity.

Conclusions. Although sleepwalking, night terrors, enuresis, and body rocking dramatically decreased during childhood, somniloquy, leg restlessness, and sleep bruxism were still highly prevalent at age 13 years, paralleling results found in adults. Sleepwalking, night terrors, and somniloquy are conditions often found together. The only robust gender difference was for enuresis. High anxiety scores in parasomnias are reported for the first time in a large, controlled study. Sociodemographic variables do not seem to play a major role in the occurrence of parasomnias. Pediatrics 2000; 106:67-74; sleep disorders, parasomnias, epidemiology, gender differences, anxiety, childhood, adolescence.

ABBREVIATIONS. RLS, restless legs syndrome; FAI, Family Adversity Index.

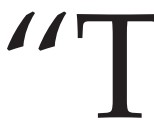
The parasomnias consist of clinical disorders that are not abnormalities of the processes responsible for sleep and awake states per se but, rather, are undesirable physical phenomena that occur predominantly during sleep." ${ }^{\prime 1}$

From the *Centre d'Étude du Sommeil, Hôpital du Sacré-Cœur, Montréal; ‡Groupe de Recherche en Inadaptation Psychosociale Chez l'Enfant; and §Département de Psychiatrie, Université de Montréal, Québec, Canada. Received for publication Aug 12, 1999; accepted Aug 12, 1999.

Reprint requests to (J.M.) Centre d'Étude du Sommeil, 5400 Boul, Gouin Ouest, Hôpital du Sacré-Coeur, Montréal, Québec, Canada H4J 1C5. E-mail: montjacq@crhsc.umontreal.ca

PEDIATRICS (ISSN 0031 4005). Copyright () 2000 by the American Academy of Pediatrics.
Parasomnias in children include most commonly: sleepwalking, night terrors, somniloquy, enuresis, sleep bruxism, and body rocking. Besides insomnia and frequent nocturnal awakenings, they are considered to be the most frequent sleep disorders of childhood. ${ }^{2}$ Because most parasomnias occur in otherwise healthy children and often disappear in adolescence, they are usually considered transient disruptive phenomena rather than medical conditions. However, when these nighttime events occur frequently, they may impair sleep continuity and reduce the recuperative value of sleep leading to daytime fatigue and somnolence.

Somniloquy consists of talking during sleep. It is the most frequent parasomnia and is often considered a universal experience. Reimão and Lefévre ${ }^{3}$ surveyed a representative sample of 2022 schoolaged children from 3 to 10 years old from the São Paulo region. They noted that approximately one half of the children presented somniloquy at least once a year, and that $<10 \%$ of the sample presented somniloquy every night. "Sleepwalking consists of a series of complex behaviors that are initiated during slow-wave sleep and result in walking during sleep." ${ }^{1}$ Motor behaviors can range from sitting up in bed to an apparent frantic attempt to escape. Klackenberg $^{4}$ studied a representative sample of 212 Swedish children 6 to 16 years old, and found that the greatest prevalence of sleepwalking was $16.7 \%$ at age 12 years. Night terrors (also called pavor nocturnus) are best described as arousal responses occurring early during the night and are associated with the feeling of fear, a loud piercing scream, and an autonomic activation manifested by tachycardia and sudation. Vela-Bueno et $\mathrm{al}^{5}$ studied 487 schoolchildren from Madrid representative of different socioeconomic groups. They reported that $6.2 \%$ of the children from 6 to 12 years of age presented at least 1 night terror episode per year.

Enuresis or bedwetting is characterized by the presence of involuntary micturition during sleep in individuals with normal waking bladder control. Enuresis is diagnosed as an abnormal condition when persistent bedwetting occurs after 5 years old. It is generally accepted that nocturnal enuresis occurs in $30 \%$ of 4 -year-olds, $10 \%$ of 6 -year-olds, $5 \%$ of 10 year-olds, and $3 \%$ of 12 -year-olds. ${ }^{6-13}$ Finally, there are 2 parasomnias characterized by repetitive motor activity occurring during sleep. "Sleep bruxism is a stereotyped movement disorder characterized by grinding or clenching of the teeth during sleep."1 It is often associated with tooth wear and/or temporal 
mandibular pain. Reding et $\mathrm{al}^{14}$ reported that $15.1 \%$ of 1157 university students had a history of bruxism between 3 and 17 years of age. Nocturnal body rocking represents rhythmic movements of the axial muscles in the back and forth or right and left motion occurring mostly during the transition from wakefulness to sleep. Sallustro and Atwell ${ }^{15}$ reported that $19.1 \%$ of 483 children from 3 months to 6 years old seen for their regular medical examination were body rockers.

In the present study, leg restlessness at bedtime was also included as a parasomnia. The definition used here was derived from the clinical assessment of restless legs syndrome (RLS) in adult populations, because there are no specific criteria for RLS in children. ${ }^{16}$ The presence of leg restlessness at bedtime is the major clinical characteristic of RLS. The final diagnosis of this condition also includes the worsening of symptoms at rest with at least temporary relief by activity and the worsening of symptoms at bedtime or during the night. ${ }^{17}$ RLS is currently considered a parasomnia of adulthood, but there is increasing evidence that it also occurs in children. Two recent studies ${ }^{18,19}$ on adult RLS patients showed that symptoms first appeared before 10 years old in 13.5\% and $18 \%$ of all cases, respectively. There is no available data in the literature on the prevalence of leg restlessness at bedtime during childhood and preadolescence.

The occurrence of parasomnias has been reported to increase with anxiety. ${ }^{20}$ As determined by Rorschach tests, children suffering from sleepwalking have more inhibited aggression and a more developed mental defense against anxiety. ${ }^{4}$ In a clinical study, adult patients with night terrors had significantly higher anxiety scores on the Crown-Crisp experiential index, compared with a normal population. ${ }^{21}$ According to Rosen et al, ${ }^{22}$ children with night terrors may be reacting partly to significant life events over which they have little control, such as separation, divorce, parental discord, or family moves. Finally, numerous studies have shown that family disruption, low parental education, or low social class are positively associated with the presence of parasomnias, especially to enuresis. . $^{6,13,23-26}$

There have been many studies on the prevalence of a single parasomnia in large samples of randomly selected normal children, but this is the first study to evaluate simultaneously the prevalence of the most frequent parasomnias in a large, randomly stratified sample of normal children with the same methods of investigation. The major aims of this study were: 1) to document the prevalence and developmental aspects of the most frequent parasomnias in the same children between 3 and 13 years of age, and 2) to assess gender differences, relationships between parasomnias, and associations with anxiety and family adversity in 11-year-old children.

\section{METHODS}

\section{Subjects}

Subjects were drawn from a longitudinal study of children from 6 to 16 years old. ${ }^{27-29}$ This survey constitutes a randomly stratified, proportional sample of 2000 children selected from
French-language school boards to be representative of all 11 administrative regions of Québec and of both urban and rural settings. The present analyses are based on results available for 1353 subjects ( 664 boys and 689 girls) for whom mothers had completed questions concerning demographics, parasomnias, and anxiety level. The remaining 647 subjects were not significantly different from the participants in this study in terms of gender distribution; geographical location; and fathers' socioeconomic status, profession, and age at the birth of the child. This study was approved by the review board for human subjects of the Université de Montréal.

\section{Instruments and Procedures}

\section{Parasomnias}

In the fifth year of the longitudinal study, children were 10 years old. Retrospective questions about the presence of each parasomnia, ie, sleepwalking, night terrors, somniloquy, enuresis, bruxism, and body rocking were added to the annual questionnaire administered to mothers and intended to cover the period between 3 and 10 years of age. At ages 11, 12, and 13 years, mothers were asked about the presence of those parasomnias and also about the presence of leg restlessness at bedtime during the previous year. Age of onset was defined as the age when a given parasomnia was first reported (3-10,11,12, or 13 years old), and age of disappearance was defined as the last time the parasomnia was reported. They had to specify the frequency of each parasomnia on a 4-level scale (frequently, sometimes, seldom, or never). Nonnumerical frequency categories were used to assess childhood parasomnias, because it is difficult to obtain exact frequencies, especially for the retrospective questions. All parasomnias were dichotomized by the pairing of choices never/seldom (scored 0) and sometimes/frequently (scored 1 ).

\section{Anxiety Scale}

At age 11 years, child behaviors were rated by the mother using the Social Behavior Questionnaire. ${ }^{30}$ The mother indicated on a 3-unit scale whether each brief description frequently applied, occasionally applied, or never applied to the behavior of the child. Anxiety was measured with 6 items ( $\alpha=.67$ for girls and $\alpha=.65$ for boys): 1) worried, worried about many things; 2 ) tends to do things on his own, solitary; 3) unhappy or distressed; 4) tends to be fearful or afraid of new things or new situations; 5) easily cries; and 6) stares into space. The anxiety score derived from these 6 items can vary from 0 to $12 .{ }^{31}$ The scale was originally created by Rutter $^{32}$ and adapted by Behar and Stringfield, ${ }^{33}$ and Tremblay et al..$^{30}$ It has been shown to correlate with cardiovascular reactivity, ${ }^{34}$ and to be quite stable from school entry to early adolescence. ${ }^{35}$

\section{Family Adversity Index (FAI)}

The FAI was also completed at 11 years of age. It is a composite measure, ranging between 0 and 1 (higher scores indicating greater disadvantage). It was computed from information provided by mothers pertaining to family structure, parental occupation, parental education level, and parental age at birth of the child. The scale was created by Tremblay et $\mathrm{al}^{30}$ and used in a number of longitudinal studies. It has been shown to be associated with cardiovascular reactivity ${ }^{36}$ and to predict problem behaviors during childhood and adolescence. ${ }^{29,37}$

\section{Statistical Analyses}

To study the prevalence and developmental aspects of parasomnias, the analysis was limited to subjects for whom data for a given parasomnia at 11,12 , and 13 years of age and retrospective data (3-10 years of age) were all available. A complete set of data were obtained for sleepwalking $(n=840)$, night terrors $(n=860)$, somniloquy $(n=787)$, enuresis $(n=870)$, bruxism $(n=712)$, and body rocking $(n=843)$. No retrospective data were available for leg restlessness $(n=967)$. For ages 11 to 13 years inclusively, the Cochran $Q$ test was used to assess the variation in the prevalence of each parasomnia as a function of age; subsequently, a McNemar test was used for posthoc comparisons to specify at what age changes occurred, if any. Bonferroni's corrections were applied to the posthoc comparisons (Table 1) to take into account the number of comparisons $(n=6)$ for each parasomnia. Retrospective data 
TABLE 1. Prevalence of Parasomnias at Various Ages in the Same Children

\begin{tabular}{cccccccc}
\hline $\begin{array}{c}\text { Age } \\
\text { (in Years) }\end{array}$ & $\begin{array}{c}\text { Sleepwalking } \\
n=840\end{array}$ & $\begin{array}{c}\text { Night Terrors } \\
n=860\end{array}$ & $\begin{array}{c}\text { Somniloquy } \\
n=787\end{array}$ & $\begin{array}{c}\text { Leg Restlessness } \\
n=967\end{array}$ & $\begin{array}{c}\text { Enuresis } \\
n=870\end{array}$ & $\begin{array}{c}\text { Sleep Bruxism } \\
n=712\end{array}$ & $\begin{array}{c}\text { Body Rocking } \\
n=843\end{array}$ \\
\hline $3-10$ & $77(9.2 \%)$ & $126(14.7 \%)$ & $292(37.1 \%)$ & - & $134(15.4 \%)$ & $137(19.2 \%)$ & $129(15.3 \%)$ \\
11 & $59(7.0 \%)$ & $33(3.8 \%)$ & $256(32.5 \%)$ & $182(18.8 \%)$ & $33(3.8 \%)$ & $98(13.8 \%)$ & $26(3.1 \%)$ \\
12 & $57(6.8 \%)$ & $20(2.3 \%)$ & $237(30.1 \%)$ & $154(15.9 \%)$ & $20(2.3 \%)$ & $80(11.2 \%)$ & $27(3.2 \%)$ \\
13 & $28(3.3 \%)$ & $10(1.2 \%)$ & $230(29.2 \%)$ & $170(17.6 \%)$ & $17(2.0 \%)$ & $66(9.3 \%)$ & $25(3.0 \%)$ \\
Overall $^{*}$ & $116(13.8 \%)$ & $149(17.3 \%)$ & $437(55.5 \%)$ & $307(31.7 \%)$ & $137(15.7 \%)$ & $200(28.1 \%)$ & $145(17.2 \%)$ \\
$P$ value & $<.001$ & $<.001$ & NS & NS & $<.001$ & $<.001$ & NS \\
\hline
\end{tabular}

NS indicates not significant.

* Cochran Q test (for ages 11-13 years inclusively).

are reported but were not considered for statistical comparisons, because they covered a large age range (3-10 years).

Data for age 11 years from 1353 subjects ( 664 boys and 689 girls) were used to: 1) study the association between parasomnias; 2) assess gender differences; and 3) evaluate the difference between parasomniacs and nonparasomniacs on anxiety scores $(n=1337)$ and on the FAI $(n=1288)$. Pearson $\chi^{2}$ tests were used to evaluate gender differences for each parasomnia. Contingency coefficients were used to characterize the strength of the association between 2 parasomnias. Student's $t$ tests for independent samples were used to compare anxiety scores and FAI for subjects afflicted or not afflicted with each of the parasomnias. Bonferroni's corrections were applied to both sets of comparisons $(n=7)$. We used Statistica for Windows (Statsoft, Inc, Tulsa, OK) for statistical analyses.

\section{RESULTS}

Developmental Aspects: Prevalence and Ages of Onset and of Disappearance

Table 1 presents the prevalence of parasomnias when children were 3 to 10 years old (retrospective data) and later, when they were 11,12, and 13 years old (prospective data). In young children (3-10 years old), the most frequent parasomnias were somniloquy and bruxism and the least frequent was sleepwalking. In older children (13 years old), the most frequent parasomnias were somniloquy and leg restlessness and the least frequent were sleepwalking, night terrors, enuresis, and body rocking. Cochran Q tests revealed significant age effects in the prevalence of sleepwalking, night terrors, enuresis, and sleep bruxism between ages 11 and 13 years. Posthoc comparisons revealed that the prevalence of sleepwalking was significantly lower at age 13 years, compared with ages $11(P<.001)$ and $12(P<.001)$ years. Night terrors were significantly less frequent in children 13 years old, compared with children 11 years old $(P<$ $.001)$. There were significantly fewer bruxers in children 13 years old $(P<.001)$ than in children 11 years old. Finally, there were significantly fewer enuretics at age 13 years than at ages $11(P<.001)$ and $12(P<$ .01) years, respectively.

Table 2 presents the ages of onset and of disappearance for each parasomnia. The total $n$ of each column represents the number of children afflicted with that particular parasomnia at 1 time or another (Table 1). For most parasomniacs, symptoms first appeared between ages 3 and 10 years. Night terrors, enuresis, and body rocking had mostly disappeared by age 10 years, whereas sleepwalking and bruxism decreased rather gradually and were still persisting at age 13 years in $24.1 \%$ of sleepwalkers and $33.0 \%$ of bruxers, respectively. The prevalence of leg restlessness is relatively stable from ages 11 to 13 years. However, a large number of new cases and of disappearance at ages 11,12, and 13 years suggests a great variability in the expression of this symptom at these ages. At age 13 years, somniloquy was still persisting in $52.6 \%$ of somniloquists.

\section{Gender Differences, Relationships Between \\ Parasomnias, and Associations With Anxiety and Family Adversity (at Age 11 Years)}

Pearson $\chi^{2}$ tests revealed statistically significant gender differences for leg restlessness $(P<.05)$, enuresis $(P<.001)$, and somniloquy $(P<.05)$. Significantly more girls than boys had leg restlessness at age 11 years $(56.8 \%$ vs $43.2 \%)$. Conversely, there were nearly 3 times more enuretics boys $(73.9 \%)$ than girls $(26.1 \%)$, and more boys ( $53.3 \%$ vs $46.7 \%$ ) were somniloquists. No significant gender differences were found for the prevalence of sleepwalking, night terrors, sleep bruxism, and body rocking.

Contingency coefficients represent the strength of the associations between parasomnias. The only sig-

TABLE 2. Development Aspects: Ages of Onset and of Disappearance for Children Afflicted With a Parasomnia

\begin{tabular}{lccccccc}
\hline $\begin{array}{c}\text { Age } \\
\text { (in Years) }\end{array}$ & $\begin{array}{c}\text { Sleepwalking } \\
n=116\end{array}$ & $\begin{array}{c}\text { Night Terrors } \\
n=149\end{array}$ & $\begin{array}{c}\text { Somniloquy } \\
n=437\end{array}$ & $\begin{array}{c}\text { Leg Restlessness } \\
n=307\end{array}$ & $\begin{array}{c}\text { Enuresis } \\
n=137\end{array}$ & $\begin{array}{c}\text { Sleep Bruxism } \\
n=200\end{array}$ & $\begin{array}{c}\text { Body Rocking } \\
n=145\end{array}$ \\
\hline Onset & & & & & & & \\
$3-10$ & $77(66.4 \%)$ & $126(84.6 \%)$ & $292(66.8 \%)$ & - & $134(97.8 \%)$ & $137(68.5 \%)$ & $129(89.0 \%)$ \\
11 & $20(17.2 \%)$ & $14(9.4 \%)$ & $65(14.9 \%)$ & $182(59.3 \%)$ & $3(2.2 \%)$ & $30(15.0 \%)$ & $6(4.1 \%)$ \\
12 & $15(12.9 \%)$ & $6(4.0 \%)$ & $43(9.8 \%)$ & $61(19.9 \%)$ & $0 \%$ & $23(11.5 \%)$ & $8(5.5 \%)$ \\
13 & $4(3.5 \%)$ & $3(2.0 \%)$ & $37(8.5 \%)$ & $64(20.9 \%)$ & $0 \%$ & $10(5.0 \%)$ & $2(1.4 \%)$ \\
Disappearance & & & & & & \\
$3-10$ & $27(23.8 \%)$ & $100(67.1 \%)$ & $56(12.8 \%)$ & - & $103(75.2 \%)$ & $57(28.5 \%)$ & $103(71.0 \%)$ \\
11 & $21(18.1 \%)$ & $22(14.8 \%)$ & $71(16.3 \%)$ & $61(19.9 \%)$ & $13(9.5 \%)$ & $32(16.0 \%)$ & $8(5.5 \%)$ \\
12 & $40(34.5 \%)$ & $17(11.4 \%)$ & $80(18.3 \%)$ & $76(24.8 \%)$ & $4(2.9 \%)$ & $45(22.5 \%)$ & $9(6.2 \%)$ \\
Persisting & $28(24.1 \%)$ & $10(6.7 \%)$ & $230(52.6 \%)$ & $170(55.4 \%)$ & $17(12.4 \%)$ & $66(33.0 \%)$ & $25(17.2 \%)$ \\
\hline
\end{tabular}

For each parasomnia, the total percentage of cases for ages of onset and of disappearance equals 100\% (of note is that a parasomnia may alternatively disappear and reappear). Children for whom mothers reported a parasomnia at age 13 years are defined as persisting cases. 
nificant associations were for sleepwalking and somniloquy (.26), sleepwalking and night terrors (.21), somniloquy and night terrors (.18), and somniloquy and sleep bruxism (.11). At age 11 years, $81 \%$ percent of sleepwalkers talked in their sleep, while $16 \%$ of somniloquists also walked during their sleep. Seventeen percent of sleepwalkers suffered from night terrors, while $36.0 \%$ of night terrors sufferers had sleepwalking episodes. Seven percent of somniloquists suffered from night terrors, while $80 \%$ of night terrors sufferers also reported somniloquy. Fourteen children, $1.0 \%$ of the total sample, simultaneously reported sleepwalking, somniloquy, and night terrors. Finally, $19.8 \%$ of somniloquists were bruxers, while $44.4 \%$ of bruxers were somniloquists. At age 11 years, leg restlessness, body rocking, and enuresis were not significantly associated with each other or with any other parasomnia.

Comparisons of parasomniacs and nonparasomniacs on anxiety scores and FAI at age 11 years are presented in Table 3. Children suffering from night terrors, somniloquy, leg restlessness, sleep bruxism, or body rocking had significantly higher anxiety scores than did children without these disorders. Sleepwalking or enuresis was not associated with significantly higher anxiety scores. The FAI was not significantly different for children afflicted or not afflicted with any of the 7 parasomnias studied.

\section{DISCUSSION}

\section{Prevalence of Parasomnias}

Results obtained in the present study showed that parasomnias represent a group of sleep disorders that are highly prevalent between the ages of 3 and 13 years. Indeed, $78 \%$ of all children studied had at least 1 childhood parasomnia.

TABLE 3. Mean Anxiety Scores and Family FAI (at Age 11 Years)

\begin{tabular}{|c|c|c|c|c|c|}
\hline & \multicolumn{2}{|c|}{ Parasomniacs } & \multicolumn{2}{|c|}{ Nonparasomniacs } & \multirow{2}{*}{$\begin{array}{c}P^{*} \\
\text { Value }\end{array}$} \\
\hline & $n$ & $\begin{array}{l}\text { Mean } \\
( \pm S D)\end{array}$ & $n$ & $\begin{array}{l}\text { Mean } \\
( \pm S D)\end{array}$ & \\
\hline \multicolumn{6}{|c|}{ Sleepwalking } \\
\hline Anxiety & 82 & $3.8( \pm 2.3)$ & 1256 & $3.3( \pm 2.2)$ & NS \\
\hline FAI & 76 & $.28( \pm .25)$ & 1212 & $.28( \pm .25)$ & NS \\
\hline \multicolumn{6}{|c|}{ Night terrors } \\
\hline Anxiety & 39 & $5.0( \pm 2.3)$ & 1299 & $3.3( \pm 2.2)$ & $<.001$ \\
\hline FAI & 37 & $.24( \pm .21)$ & 1251 & $.28( \pm .25)$ & NS \\
\hline \multicolumn{6}{|l|}{ Somniloquy } \\
\hline Anxiety & 419 & $3.7( \pm 2.2)$ & 919 & $3.2( \pm 2.2)$ & $<.01$ \\
\hline FAI & 408 & $.28( \pm .25)$ & 880 & $.27( \pm .25)$ & NS \\
\hline \multicolumn{6}{|c|}{ Leg restlessness } \\
\hline Anxiety & 242 & $4.0( \pm 2.3)$ & 1096 & $3.2( \pm 2.2)$ & $<.001$ \\
\hline FAI & 231 & $.29( \pm .26)$ & 1057 & $.27( \pm .25)$ & NS \\
\hline \multicolumn{6}{|l|}{ Enuresis } \\
\hline Anxiety & 45 & $3.4( \pm$ & 1293 & $3.4( \pm 2.2)$ & NS \\
\hline FAI & 43 & $.27( \pm .23)$ & 1245 & $.28( \pm .25)$ & NS \\
\hline \multicolumn{6}{|c|}{ Sleep bruxism } \\
\hline Anxiety & 186 & $3.9( \pm 2.4)$ & 1152 & $3.3( \pm 2.2)$ & $<.01$ \\
\hline FAI & 179 & $.26( \pm .25)$ & 1109 & $.28( \pm .25)$ & NS \\
\hline \multicolumn{6}{|c|}{ Body rocking } \\
\hline Anxiety & 42 & $4.3( \pm 2.5)$ & 1296 & $3.3( \pm 2.2)$ & $<.05$ \\
\hline FAI & 40 & $.28( \pm .25)$ & 1248 & $.28 \mathrm{t}( \pm .25)$ & NS \\
\hline
\end{tabular}

SD indicates standard deviation; NS, not significant.

* Student's $t$ test for independent samples.

\section{Sleepwalking}

For sleepwalking, the overall prevalence found in the present study was similar to that previously reported. ${ }^{4,24,38,39}$ As also noted in previous studies, ${ }^{24,40,41}$ it was found that sleepwalking commonly begins in childhood and less frequently in adolescence. In addition, in most cases, the condition is outgrown before the age of 10 years. Nevertheless, at age 13 years, sleepwalking was still persisting in $24.1 \%$ of sleepwalkers (3.3\% of the total sample). Sleepwalking and night terrors were originally reported to be more frequent in boys than in girls ${ }^{20,42,43}$; however, these studies were based on clinical impressions rather than on epidemiologic data. No significant gender differences were seen for either sleepwalking or night terrors in the present study, as also found in numerous previous studies. ${ }^{4,5,24,25,38,39,44-47}$

\section{Night Terrors}

There are major discrepancies in the literature with regards to the prevalence of night terrors. ${ }^{4,5,25,38,39,44,48,49}$ Prevalence studies of night terrors are difficult to compare, not only because of the differences in sampling methods, but primarily because of differences in defining night terrors. The prevalence of night terrors should be interpreted with caution because nightmares may at times be confounded with night terrors, especially for the retrospective data (ages 3-10 years). The overall prevalence found in the present study $(17.3 \%)$ clearly demonstrates that night terrors are a highly prevalent parasomnia of children. Contrary to sleepwalking, night terrors are dramatic and more likely to be detected and accurately reported by parents. ${ }^{45,50}$ At age 13 years, night terrors were still persisting in $6.7 \%$ (1.2\% of the total sample) of night terrors sufferers. This is lower than the estimate made by DiMario and Emery ${ }^{50}$ who found that night terrors persisted into adolescence in 36\% of their cases. However, their estimate comes from a cohort of children referred to a pediatric clinic for sleep disturbances and represents a particular subgroup of children, whereas our sample is more representative of the general population.

\section{Somniloquy}

Somniloquy is a common condition in both children and adults. ${ }^{51}$ It is apparently so widespread that it is difficult to find individuals in college populations who have never talked during their sleep..$^{52}$ The overall prevalence found in the present study for children ages 3 to 13 years (55.5\%) was similar to that reported by others. ${ }^{3,38}$ Although Adair and Bauchner ${ }^{42}$ reported that somniloquy was more prevalent in children ages 4 to 5 years, 2 studies have found no effect of age on the prevalence of somniloquy.,38 Results of the present study showed no significant age effect between the ages of 11 and 13 years. In a recent epidemiologic study of 4866 normal adults of the United Kingdom, somniloquy was reported by $24.0 \%$ of the sample. ${ }^{53}$ Therefore, the slight progressive decrease reported in our study (from $37.1 \%$ between 3 and 10 years of age to $29.2 \%$ at 13 years of age) is concordant with the latter prevalence found 
in adults. We have no simple explanation for the slightly higher prevalence of somniloquy in males.

The present study confirms results from epidemiologic studies in children ${ }^{38,45,48,50,54}$ concerning an association between sleepwalking, night terrors, and somniloquy. A predisposition to awake confused out of deep slow wave sleep likely puts a child at risk for developing both sleepwalking and night terrors and may explain the common cooccurrence of these parasomnias. Confusional arousals may be, in turn, associated with vocalizations identified by the mother as somniloquy.

\section{Leg Restlessness}

RLS is usually considered a disorder of middleaged or elderly people. However, cases of RLS have been reported in children. ${ }^{16}$ In the present study, $31.7 \%$ of children were identified as having leg restlessness at bedtime between ages 11 and 13 years. The prevalence found for 13-year-olds is concordant with a large epidemiologic study that was previously conducted across Canada, where the prevalence was found to be $9 \%$ for subjects in their 20s, with a progressive increase thereafter. ${ }^{55}$ Interestingly, only $6.1 \%$ of the sample were identified as having leg restlessness for 3 consecutive years. The presence of leg restlessness at bedtime is highly suggestive of a diagnosis of the RLS, although there was no question in this survey about the worsening of symptoms at rest and the worsening of symptoms in the evening or during the night. However, it should be stressed that in a recent study, Picchietti and coworkers ${ }^{56}$ noted that only a small proportion of children with RLS present the International RLS Study Group criteria ${ }^{17}$; therefore, these criteria should not be considered mandatory for the diagnosis in this population. It may be surprising that in a large portion of children reporting leg restlessness, symptoms disappeared later on during the survey. This finding is actually common in RLS. It has been known since the early description by Ekbom ${ }^{57}$ that, in the early stages of this condition, symptoms may disappear for several months or even for years and reappear suddenly without any explanation for either the sudden remission or reoccurrence of the symptomatology.

A gender difference was found for leg restlessness, with more females afflicted with this condition. There are no data in the literature for leg restlessness at bedtime in children, but a similar sex difference has been noted in adults. ${ }^{55}$ In adults, it has been suggested ${ }^{58}$ that the higher prevalence for women may be explained by the association of leg restlessness with menstruation, pregnancy, and/or menopause. Results of the present study showing a difference favoring females in prepubertal children suggest that these hormonal changes taking place at specific times in the adult life do not entirely explain the gender difference seen in this condition. Leg restlessness at bedtime was not found to be associated with any other parasomnia.

\section{Enuresis}

In the present study, no differentiation was made between primary and secondary enuresis and be- tween children with or without abnormal bladder control while awake. However, our overall prevalence $(15.7 \%)$ is consistent with results of other studies showing frequencies between $11 \%$ and $18.9 \% .8,12,13,23,59,60$ Prevalence rates found in this longitudinal study of children 11, 12, and 13 years old (between $2.0 \%$ and $4.0 \%$ ) are also similar to those reported in other longitudinal studies. ${ }^{7,9,11}$ When we considered all enuretic children for whom the data were available from ages 3 to 13 years, we found that $\sim 88 \%$ of all enuretic children had outgrown this condition by 13 years old. The prevalence rate found at age 13 years $(2.0 \%)$ is similar to the prevalence rate of $1.5 \%$ to $3.0 \%$ found in an adult population. ${ }^{61}$ The present results confirm the well-established gender difference in enuresis, with more males being affected. $8,23,26,59,60,62$ Enuresis has previously been found to be associated with sleepwalking in naval recruits. ${ }^{63}$ Klackenberg ${ }^{54}$ also found a significant covariation between sleepwalking and enuresis between ages 4 and 16 years. However, he noted that the 2 conditions rarely coincide in time, and sleepwalking becomes more evident after bladder control is achieved. In the present study, no association was found between enuresis and any other parasomnia, including sleepwalking.

\section{Bruxism}

Results of the present study showed a high prevalence of sleep bruxism in children and a progressive decrease with age during childhood and preadolescence. These results are in agreement with those previously published. ${ }^{14,38,39}$ At age 13 years, the prevalence was $9.2 \%$, which is comparable to results obtained in young adults. ${ }^{55}$ This latter epidemiologic study also reported a progressive decrease in the prevalence of bruxism from young adulthood to old age. ${ }^{55}$ As found in previous studies of sleep bruxism ${ }^{14,38,54,64,65}$ or body rocking, ${ }^{15,66,67}$ no gender differences were found for these conditions in this study. There has been no previous study of the association between sleep bruxism and other parasomnias in a large population of randomly selected children. Questionnaire studies have reported an association among sleep bruxism, somniloquy, and enuresis in children $^{68}$ and between sleep bruxism and leg restlessness in adults. ${ }^{69}$ In the present study, a significant association was found only between sleep bruxism and somniloquy, and indeed, nearly $20 \%$ of all somniloquists were reported to grind their teeth during sleep. It should be stressed that both conditions involve orofacial muscles.

\section{Body Rocking}

Body rocking is a disorder of early childhood and disappears in $\sim 70 \%$ of the cases by age 10 years. However, $17 \%$ of body rockers still performed their rhythmical activity at age 13 years. Few cases of body rocking have been reported in adults, ${ }^{70}$ and, in most of these cases, the condition was already present during childhood. As for leg restlessness, body rocking was not found to be associated with any other parasomnia. 
Influence of Social Factors and Psychological Factors

It was suggested that social factors, such as family structure or socioeconomic status, may play a role in the presence of behavioral problems in children in the awake state. ${ }^{71,72}$ In the present study, we looked at the relationship between family adversity and all parasomnias at age 11 years. The FAI, including family structure, parental occupation, parental education level, and parental age at the birth of the child, was not significantly correlated with the presence of any of the parasomnias. As in previous studies, ${ }^{4,15,38,39}$ no correlations were found between sociodemographic variables and sleepwalking, night terrors, somniloquy, leg restlessness, sleep bruxism, or body rocking.

There are controversies in the literature regarding the contribution of social factors to the cause of enuresis. It is widely believed that enuresis is a multicausal condition involving genetic, organic, developmental, and psychosocial factors. Rutter et $\mathrm{al}^{73}$ suggested that these associations might be secondary to some other factors like differences in the frequency of stressful events or of disruptive life experiences. Gross and Dornbusch ${ }^{23}$ found that social class was related to enuresis at all ages from 6 through 17 years, and for both sexes. Many other studies have shown a positive association between the presence of nocturnal enuresis and family disruption, low parental education, or low social class. ${ }^{6,13,26,74}$ In the present study, as in several other studies, $38,39,75-77$ no such association was found. Gross and Dornbusch ${ }^{23}$ argued that a greater understanding of the cause of enuresis necessitates specific information about individual development and the corresponding social stress.

Adult parasomnias are often associated with psychopathology, whereas childhood parasomnias are primarily related to genetic and developmental factors. ${ }^{40-45}$ However, psychological factors have also been related to sleep problems in children and adolescents. ${ }^{46,78-80}$

In the present study, the association between high anxiety scores and the presence of each parasomnia was examined. High anxiety levels were previously reported in adults with night terrors ${ }^{21,81}$ or bruxism. ${ }^{82-84}$ Anxiety has also been associated with night terrors $^{85}$ and body rocking ${ }^{86}$ in children, but only from clinical reports. Overall, we found significant associations between anxiety level and all parasomnias studied, except for sleepwalking and enuresis. Anxiety has been previously associated with sleepwalking. ${ }^{4,44}$ In the present study, the significant difference between sleepwalkers and nonsleepwalkers on anxiety score disappeared after Bonferroni's correction was applied. In contrast, the present results on anxiety level in enuretic children are in contradiction with those of Fergusson and Horwood. ${ }^{11}$ This difference might be explained by the source of the behavioral measures that composed the anxiety scale; theirs were provided by the mother, the teacher, and the child himself, whereas in the present study, the rating was done exclusively by the mother.

\section{CONCLUSION}

Parasomnias are highly prevalent in children between the ages of 3 and 13 years. Although night terrors and enuresis decrease markedly by adolescence, sleepwalking and body rocking persist in a considerable number of cases at 13 years of age. The high prevalence rates of somniloquy, leg restlessness, and sleep bruxism during childhood also decrease (albeit less dramatically) to draw near, at age 13 years, the substantial prevalence found in adults. The only robust gender difference is for enuresis. Results of the associations between parasomnias suggest that some conditions are strongly associated with each other, such as sleepwalking, night terrors, and somniloquy, and may represent 1 type of parasomnias, whereas leg restlessness, body rocking, sleep bruxism, and enuresis would each represent unrelated clinical entities without specific association to any sleep stage. The present study confirms the presence of high anxiety levels in children suffering from night terrors and body rocking and reports it for the first time in children afflicted with somniloquy, leg restlessness, and bruxism in a large, controlled epidemiologic study. Based on the present results, sociodemographic variables do not seem to play a major role in the occurrence of parasomnias.

\section{ACKNOWLEDGMENTS}

This work was supported by the Medical Research Council of Canada and the Fonds de la Recherche en Santé du Québec.

We thank Jean Paquet, PhD, for Statistical advice; Nathalie Fréchette and Muriel Rorive for technical assistance; and Dominique Petit, $\mathrm{PhD}$, for manuscript revision.

\section{REFERENCES}

1. American Sleep Disorders Association. International Classification of Sleep Disorders, Revised: Diagnostic and Coding Manual. Rochester, MN: American Sleep Disorders Association; 1997

2. Dollinger SJ. Childhood sleep disturbances. Adv Clin Child Psychol. 1985;9:279-332

3. Reimão RN, Lefévre AB. Prevalence of sleep-talking in childhood. Brain Dev. 1980;2:353-357

4. Klackenberg G. Somnambulism in childhood-prevalence, course and behavioral correlations. Acta Paediatr. 1982;71:495-499

5. Vela-Bueno A, Bixler EO, Dobladez-Blanco B, Rubio ME, Mattison RE, Kales A. Prevalence of night terrors and nightmares in elementary school children: a pilot study. Res Commun Psychol Psychiatry Behav. 1985;10:177-188

6. Essen J, Peckham C. Nocturnal enuresis in childhood. Dev Med Child Neurol. 1976;18:577-589

7. Klackenberg G. Nocturnal enuresis in a longitudinal perspective. Acta Paediatr. 1981;70:453-457

8. Rahim SI, Cederblad M. Epidemiology of nocturnal enuresis in a part of Khartoum, Sudan: the extensive study. Acta Paediatr. 1986;75:1017-1020

9. Feehan M, McGee R, Stanton W, Silva PA. A 6-year follow-up of childhood enuresis: prevalence in adolescence and consequences for mental health. J Paediatr Child Health. 1990;26:75-79

10. Hellström AL, Hanson E, Hansson S, Hjalmas K, Jodal U. Micturition habits and incontinence in 7-year-old Swedish school entrants. Eur J Pediatr. 1990;149:434-437

11. Fergusson DM, Horwood LJ. Nocturnal enuresis and behavioral problems in adolescence: a 15-year longitudinal survey. Pediatrics. 1994;94: 662-668

12. Byrd RS, Weitzman M, Lanphear NE, Auinger P. Bed-wetting in US children: epidemiology and related behavior problems. Pediatrics. 1996; 98:414-419

13. Kalo BB, Bella H. Enuresis: prevalence and associated factors among primary school children in Saudi Arabia. Acta Paediatr. 1986;85: 1217-1222

14. Reding GR, Zepelin H, Monroe LJ. Incidence of bruxism. J Dent Res. 1966;45:1198-1204 
15. Sallustro F, Atwell CW. Body rocking, head banging, and head rolling in normal children. J Pediatr. 1978;93:704-708

16. Picchietti DL, Walters AS. Restless legs syndrome and periodic limb movement disorder in children and adolescents: comorbidity with attention-deficit hyperactivity disorder. Child Adolesc Psychiatr Clin N Am. 1996;5:729-740

17. The International Restless Legs Syndrome Study Group. Toward a better definition of the restless legs syndrome. Mov Disord. 1995;10: $634-642$

18. Walters AS, Hickey K, Maltzman J, et al. A questionnaire study of 138 patients with restless legs syndrome: the "Night-Walkers' survey. Neurology. 1996;46:92-95

19. Montplaisir J, Boucher S, Poirier G, Lavigne G, Lapierre O, Lespérance P. Clinical, polysomnographic, and genetic characteristics of restless legs syndrome: a study of 133 patients diagnosed with new standard criteria. Mov Disord. 1997;12:61-65

20. Parkes JD. The parasomnias. Lancet. 1986;2:1021-1025

21. Crisp AH, Matthews BM, Oakey M, Crutchfield M. Sleepwalking, night terrors and consciousness. Br Med J. 1990;300:360-362

22. Rosen G, Mahowald MW, Ferber R. Sleepwalking, confusional arousals, and sleep terrors in the child. In: Ferber R, Kryger M, eds. Principles and Practice of Sleep Disorders in the Child. Philadelphia, PA: WB Saunders Co; 1995:45-53

23. Gross RT, Dornbusch SM. Enuresis. In: Levine MD, Carey WB, Crocker AC, Gross RT, eds. Developmental-Behavioral Pediatrics. Philadelphia, PA: WB Saunders Co; 1983:574-586

24. Fisher BE, Wilson AE. Selected sleep disturbances in school children reported by parents: prevalence, interrelationships, behavioral correlates and parental attributions. Percept Mot Skills. 1987;64:1147-1157

25. Kahn A, Van de Merckt C, Rebuffat E, et al. Sleep problems in healthy preadolescents. Pediatrics. 1989;84:542-546

26. Rona RJ, Li L, Chinn S. Determinants of nocturnal enuresis in England and Scotland in the '90s. Dev Med Child Neurol. 1997;39:677-681

27. Vitaro F, Tremblay RE, Gagnon C. Teacher ratings of children's behaviors and teachers' management styles: a research note. J Child Psychol Psychiatry. 1995;36:887-898

28. Zoccolillo M, Tremblay RE, Vitaro F. DSM-III-R and DSM-III criteria for conduct disorder in preadolescent girls: specific but insensitive. J Am Acad Child Adolesc Psychiatry. 1996;35:461-470

29. Pagani L, Boulerice B, Tremblay RE. The influence of poverty on children's classroom placement and behavior problems. In: Brooks-Gunn J, Duncan G, eds. Consequences of Growing up Poor. New York, NY: RussellSage; 1997:311-339

30. Tremblay RE, Loeber R, Gagnon C, Charlebois P, Larivée S, LeBlanc M. Disruptive boys with stable and unstable high fighting behavior patterns during junior elementary school. J Abnorm Child Psychol. 1991;19: 285-300

31. Tremblay RE, Vitaro F, Gagnon C, Piché C, Royer N. A prosocial scale for the Preschool Behavior Questionnaire: concurrent and predictive correlates. Int J Behav Dev. 1992;15:227-245

32. Rutter M. Children's behaviour questionnaire for completion by teachers: preliminary findings. J Child Psychol Psychiatry. 1967;8:1-11

33. Behar LB, Stringfield S. A behavior rating scale for the preschool child. Dev Psychol. 1974;10:601-610

34. Dobkin P, Tremblay RE, Treiber F. Cardiovascular reactivity in low SES adolescent boys previously characterized as anxious, disruptive, anxious-disruptive, or normal during childhood. Psychother Psychosom. 2000;69:50-56

35. Gagnon C, Craig WM, Tremblay RE, Zhou RM, Vitaro F. Kindergarten predictors of boy's stable behavior problems at the end of the elementary school. J Abnorm Child Psychol. 1995;23:753-766

36. Dobkin PL, Tremblay RE, Treiber FA. Cardiovascular reactivity and adolescent boys' physical health. Pediatrics. 1998;101(3). URL: http:// www.pediatrics.org/cgi/content/full/101/3/e11

37. Mâsse LC, Tremblay RE. Kindergarten disruptive behavior, family adversity, gender and elementary school failure. Appl Psychol. 1999;23: 225-240

38. Simonds JF, Parraga H. Prevalence of sleep disorders and sleep behaviors in children and adolescents. J Am Acad Child Adolesc Psychiatry. 1982;21:383-388

39. Fisher BE, Pauley C, McGuire K. Children's Sleep Behavior Scale: normative data on 870 children in grades 1 to 6. Percept Mot Skills. 1989;68: 227-236

40. Kales A, Soldatos CR, Caldwell AB, et al. Somnambulism. Arch Gen Psychiatry. 1980;37:1406-1410

41. Cirignotta F, Zucconi M, Mondini S, Lenzi PL, Lugaresi E. Enuresis, sleepwalking, and nightmares: an epidemiological survey in the republic of San Marino. In: Guilleminault C, Lugaresi E, eds. Sleep/Wake
Disorders: Natural History, Epidemiology, and Long-Term Evolution. New York, NY: Raven Press; 1983:237-241

42. Adair RH, Bauchner H. Sleep problems in childhood. Curr Probl Pediatr. 1993;23:147-170

43. Mindell JA. Sleep disorders in children. Health Psychol. 1993;12:151-162

44. Dollinger SJ. On the varieties of childhood sleep disturbance. J Clin Child Psychol. 1982;1:107-115

45. Kales JD, Kales A, Soldatos CR, et al. Night terrors. Arch Gen Psychiatry. 1980;37:1413-1417

46. Morrison DN, McGee R, Stanton WR. Sleep problems in adolescence. J Am Acad Child Adolesc Psychiatry. 1992;31:94-99

47. Saarenpää-Heikkilä OA, Rintahaka PJ, Laippala PJ, Koivikko MJ. Sleep habits and disorders in Finnish schoolchildren. J Sleep Res. 1995;4: 173-182

48. Kurth VE, Gohler I, Knaape HH. Untersuchungen uber den pavor nocturnus bei kindern. Psychiatrie Neurologie Medizinische Psychologie. $1965 ; 17: 1-7$

49. Anders TF, Eiben LA. Pediatric sleep disorders: a review of the past 10 years. J Am Acad Child Adolesc Psychiatry. 1997;36:9-20

50. DiMario FJ Jr, Emery ES III. The natural history of night terrors. Clin Pediatr. 1987;26:505-511

51. Horne J. Annotation: sleep and its disorders in children. J Child Psychol Psychiatry. 1992;33:473-487

52. Arkin AM. Sleeptalking. In: Ellman SJ, Antrobus JS, eds. The Mind in Sleep. New York, NY: John Wiley and Sons; 1991:415-436

53. Ohayon MM, Caulet M, Priest RG. Violent behavior during sleep. J Clin Psychiatry. 1997;58:369-376

54. Klackenberg G. Incidence of parasomnias in children in a general population. In: Guilleminault C, ed. Sleep and Its Disorders in Children. New York, NY: Raven Press; 1987:99-113

55. Lavigne GJ, Montplaisir J. Restless legs syndrome and sleep bruxism: prevalence and association among Canadians. Sleep. 1994;17:739-743

56. Picchietti DL, England SJ, Walters AS, Willis K, Verrico T. Periodic limb movement disorder and restless legs syndrome in children with attention-deficit hyperactivity disorder. J Child Neurol. 1998;13:588-594

57. Ekbom KA. Restless legs: a clinical study. Acta Med Scand Suppl. 1945; 158:1-122

58. Mahowald MW, Schenck CH. Parasomnias including the restless legs syndrome. Clin Chest Med. 1998;19:183-202

59. Bower WF, Moore KH, Shepherd RB, Adams RD. The epidemiology of childhood enuresis in Australia. Br J Urol. 1996;78:602-606

60. Serel TA, Akhan G, Koyuncuoglu HR, et al. Epidemiology of enuresis in Turkish children. Scand J Urol Nephrol. 1997;31:537-539

61. Tietjen DN, Husmann DA. Nocturnal enuresis: a guide to evaluation and treatment. Mayo Clin Proc. 1996;71:857-862

62. Järvelin MR, Vikeväinen-Tervonen L, Moilanen I, Huttunen NP. Enuresis in seven-year-old children. Acta Paediatr. 1988;77:148-153

63. Pierce C, Lipcon HH. Clinical relationship of enuresis to sleepwalking and epilepsy. Arch Neurol Psychiatry. 1956;76:310-316

64. Glaros AG. Incidence of diurnal and nocturnal bruxism. J Prosthet Dent. 1981;45:545-549

65. Wruble MK, Lumley MA, McGlynn FD. Sleep-related bruxism and sleep variables: a critical review. J Craniomandib Disord Facial Oral Pain. 1989;3:152-158

66. Klackenberg G. Rhythmic movements in infancy and early childhood. Acta Paediatr Suppl. 1971;224:74-83

67. Ferber R. Familial headbanging. Sleep Res. 1988;17:176

68. Weideman CL, Bush DL, Yan-Go FL, Clark GT, Gornbein JA. The incidence of parasomnias in child bruxers versus nonbruxers. Pediatr Dent. 1996;18:456-460

69. Ware JC, Rugh JD. Destructive bruxism: sleep stage relationship. Sleep. 1988;11:172-181

70. Lapierre O, Montplaisir J, Gosselin A. Bodyrocking during REM sleep: a case study. Sleep Res. 1992;21:224

71. Garbarino J. Children and Families in the Social Environment. New York, NY: Adline Press; 1982

72. Velez CN, Johnson J, Cowen P. A longitudinal analysis of selected risk factors for childhood psychopathology. J Am Acad Child Adolesc Psychiatry. 1989;28:861-864

73. Rutter M, Yule W, Graham P. Enuresis and behavioural deviance: some epidemiological considerations. In: Kolvin I, MacKeith RC, Meadows SR, eds. Bladder Control and Enuresis, Clinics in Developmental Medicine. London, England: Heinemann; 1973:137-147

74. Shaffer D. The association between enuresis and emotional disorder: a review of the literature. In: Kolvin I, MacKeith RC, Meadows SR, eds. Bladder Control and Enuresis, Clinics in Developmental Medicine. London, England: Heinemann; 1973:118-136 
75. Oppel WC, Harper PA, Rider RV. The age of attaining bladder control. Pediatrics. 1968;42:627-641

76. Cederblad M, Rahim SI. Epidemiology of nocturnal enuresis in a part of Khartoum, Sudan. II. The intensive study. Acta Paediatr. 1986;75: 1021-1027

77. Fergusson DM, Horwood LJ, Shannon FT. Factors related to the age of attainment of nocturnal bladder control: an 8-year longitudinal study. Pediatrics. 1986;78:884-890

78. Marks PA, Monroe LJ. Correlates of adolescents poor sleepers. J Abnorm Psychol. 1976;85:243-246

79. Bertelson AD, Monroe LJ. Personality patterns of adolescent poor and good sleepers. J Abnorm Child Psychol. 1979;7:191-197

80. Dahl RE. Sleep in behavioral and emotional disorders. In: Ferber R, Kryger M, eds. Principles and Practice of Sleep Disorders in the Child.
Philadelphia, PA: WB Saunders Co; 1995:45-53

81. Fisher C, Kahn E, Edwards A, Davis DM. A psychophysiological study of nightmares and night terrors. I. Physiological aspects of the stage 4 night terror. J Nerv Ment Dis. 1973;157:75-98

82. Vernallis FF. Teeth-grinding: some relationship to anxiety, hostility, and hyperactivity. J Clin Psychol. 1955;11:389-391

83. Thaller JL. The use of the Cornell Index to determine the correlation between bruxism and the anxiety state: a preliminary report. J Periodontol. 1960;31:138-140

84. Molin C, Levi L. A psycho-odontologic investigation of patients with bruxism. Acta Odontol Scand. 1966;24:373-391

85. Dahl RE. The pharmacologic treatment of sleep disorders. Psychiatr Clin North Am. 1992;15:161-178

86. Evans J. Rocking at night. J Child Psychol Psychiatry. 1961;2:71-85

\section{WHO WILL RID US OF THESE MEDDLING MANAGERS?}

Doctors are intelligent people, who have generally worked hard ... [but] they are being treated as if they were criminally inclined and stupid into the bargain, in need of superior wisdom of the government to keep them in order. 